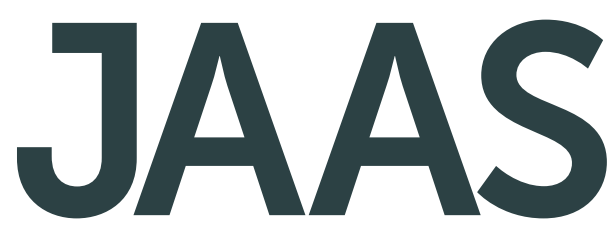

Journal of Analytical Atomic Spectrometry www.rsc.org/jaas
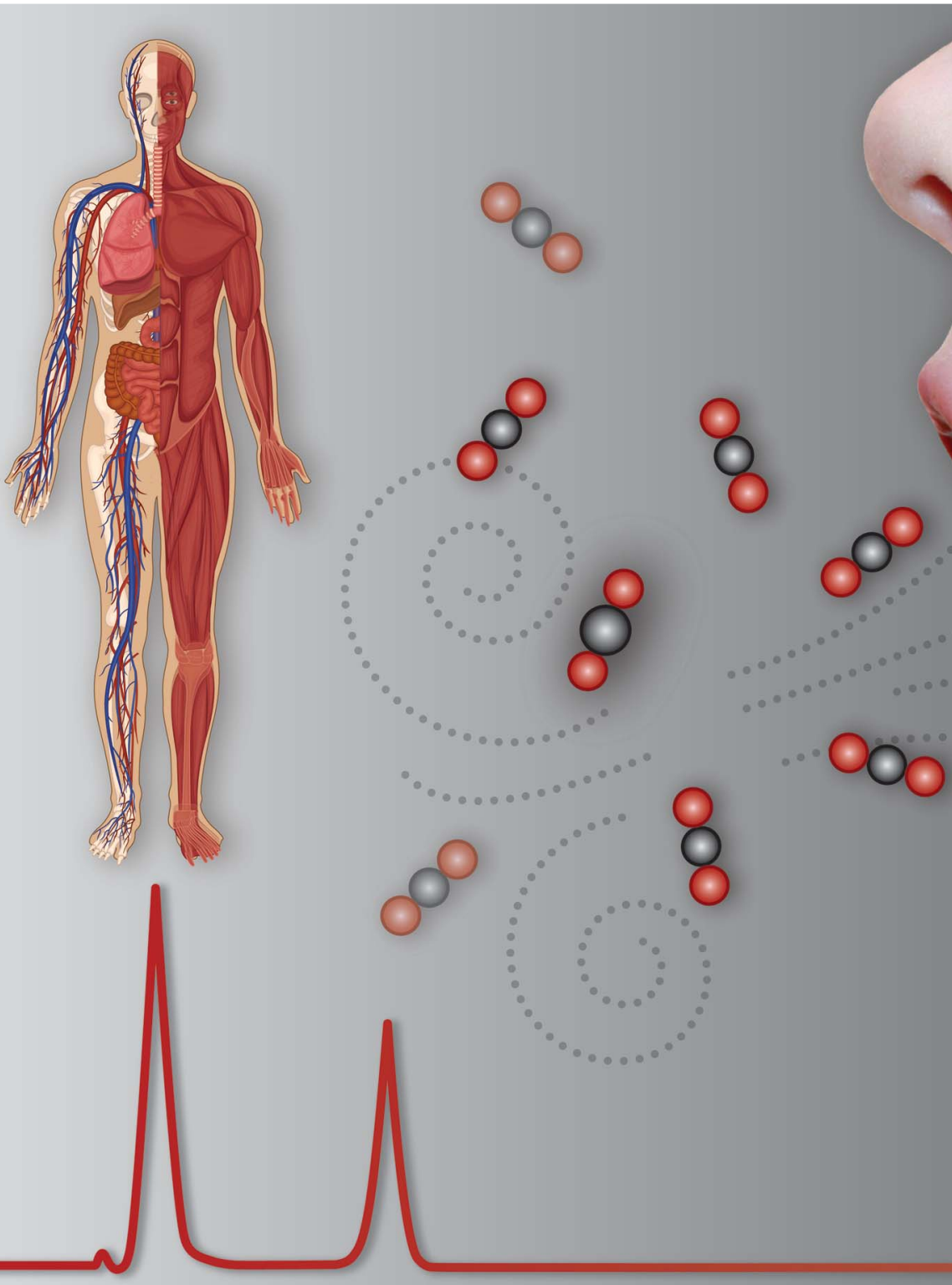

ISSN 0267-9477
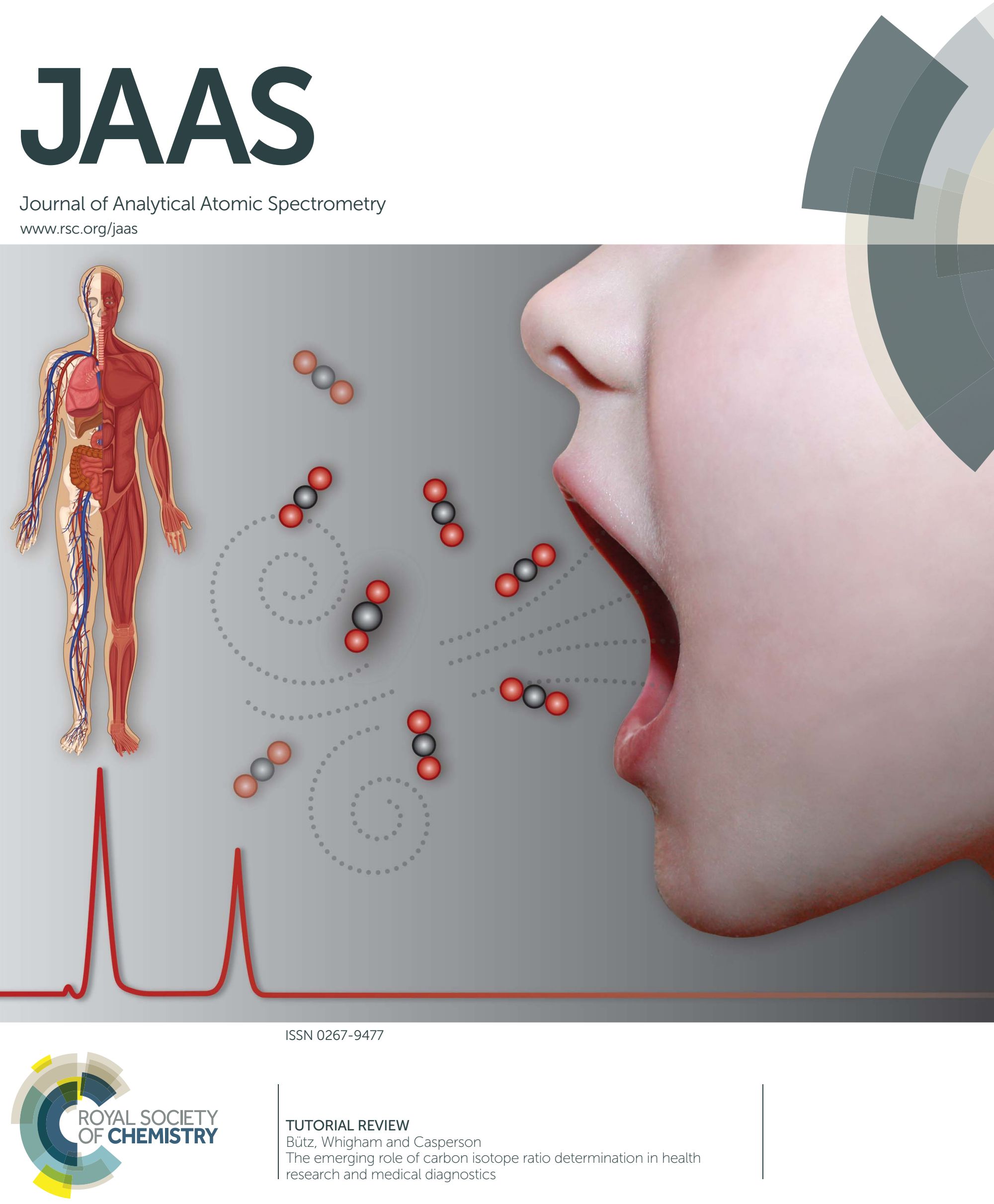
Cite this: J. Anal. At. Spectrom., 2014, 29, 594

Received 1st October 2013

Accepted 21st November 2013

DOI: 10.1039/c3ja50327e

www.rsc.org/jaas

\section{The emerging role of carbon isotope ratio determination in health research and medical diagnostics}

\begin{abstract}
Daniel E. Bütz, ${ }^{\text {*a }}$ Shanon L. Casperson ${ }^{\mathrm{b}}$ and Leah D. Whigham ${ }^{\star c}$
Variations in the isotopic signature of carbon in biological samples (e.g. breath, blood and tissues) can be used to monitor shifts in whole body metabolism. As a conservative recorder of our diet, changes in the isotopic signature of carbon in biological samples provide an objective means to distinguish dietary patterns and the relationship with diseases. In addition, metabolic discrimination of carbon within the body can be informative regarding changes in the body's metabolic fuel usage during situations where shifts in the macronutrient oxidation ratio are expected. Therefore, changes in the isotopic signature over time have proven to be a tremendously powerful and sensitive means of detecting and measuring changes in steady-state systems. As such, this review focuses on how a naturally occurring ratio of stable isotopes of carbon $\left({ }^{13} \mathrm{C} /{ }^{12} \mathrm{C}\right)$ can be used as a biomarker for nutritional and metabolic status, altered macronutrient metabolism, and health and disease.
\end{abstract}

\section{Introduction}

Carbon dioxide has long been used as a marker for health and disease, ${ }^{1}$ and the ${ }^{13} \mathrm{C} /{ }^{12} \mathrm{C}$ ratio reflects changes in diet and metabolism. ${ }^{2-4}$ Measurement of carbon in exhaled breath has progressed from the advent of capnography in the $18^{\text {th }}$ century by Tyndall using infrared light absorption to measurement of the stable isotopes of carbon by isotope ratio mass spectrometry in the $19^{\text {th }}$ century to recent advances in instrumentation that make the carbon stable isotope ratio in exhaled breath a viable biomarker for health and disease. In this review we will explore how advances in measurement of stable isotopes provide new opportunities for non-invasive, individualized biofeedback. This review focuses on naturally occurring stable isotopes of carbon and how they can be used for diagnostic, intervention, and research purposes related to health and disease. The review will cover the history of ${ }^{13} \mathrm{C} /{ }^{12} \mathrm{C}$ as a marker for health and disease; the science of isotopic fractionation at the core of these applications; regional differences in ${ }^{13} \mathrm{C} /{ }^{12} \mathrm{C}$ in diet; and the principles and research related to stable isotopes of carbon in nutrition, exercise, metabolic status, and disease.

${ }^{a}$ Department of Animal Sciences, University of Wisconsin-Madison, 1675 Observatory Drive, Madison, WI, 53706, USA. E-mail: debutz@wisc.edu

${ }^{b}$ USDA-ARS, Grand Forks Human Nutrition Research Center, 2420 2nd Ave North, Grand Forks, ND, USA

'Paso del Norte Institute for Healthy Living, 500 W. University Ave., El Paso, TX 79968, USA.E-mail: ldwhigham@utep.edu

\section{History of carbon as a marker for health and disease}

Capnography is the science of monitoring the concentration of carbon dioxide $\left(\mathrm{CO}_{2}\right)$ in respiratory gases and is based on the principle that $\mathrm{CO}_{2}$ absorbs infrared radiation. ${ }^{1}$ Capnography directly reflects the elimination of $\mathrm{CO}_{2}$ by the lungs, providing information on respiratory patterns, pulmonary perfusion and alveolar ventilation. Indirectly, it reflects the production of $\mathrm{CO}_{2}$ by tissues and the circulatory transport of $\mathrm{CO}_{2}$ to the lungs. When expired $\mathrm{CO}_{2}$ is related to the expired volume rather than time, the area under the curve represents the volume of $\mathrm{CO}_{2}$ in the breath. Over the course of a minute, this calculation yields the $\mathrm{CO}_{2}$ minute elimination, an important measure of metabolism.

Within the past 50 years, scientists have demonstrated that further insights into alterations in body metabolism can be gained by measuring the ratio of the stable isotopes of carbon (i.e. ${ }^{13} \mathrm{C} /{ }^{12} \mathrm{C}$ ) in exhaled $\mathrm{CO}_{2}$, termed the breath delta value or BDV. ${ }^{2-4}$ Until recently, measurement of the BDV has had limited clinical utility since instrumentation capable of the BDV measurement was too complex and cumbersome for widespread clinical adoption. However, within the last decade, advances in infrared spectroscopy have enabled more precise and accurate measurements of the carbon stable isotope ratio through multi-pass measurement cells termed cavity ring-down spectroscopy (CRDS). ${ }^{5}$ CRDS uses infrared laser absorption to measure the concentration of ${ }^{13} \mathrm{CO}_{2}$ and ${ }^{12} \mathrm{CO}_{2}$ carbon signals and reports not only precise and accurate total $\mathrm{CO}_{2}$ concentrations (as do capnographs in clinical use today) but also the ${ }^{13} \mathrm{CO}_{2} /{ }^{12} \mathrm{CO}_{2}$ ratio. ${ }^{5}$ 
BDV is expressed in parts per mil (\%) notation as in eqn (1):

$$
\delta=\frac{\left({ }^{13} \mathrm{C} /{ }^{12} \mathrm{C} \text { sample }-{ }^{13} \mathrm{C} /{ }^{12} \mathrm{C} \mathrm{PDB}\right)}{{ }^{13} \mathrm{C} /{ }^{12} \mathrm{C} \mathrm{PDB}} \times 1000
$$

where $\delta=\mathrm{BDV}$ and $\mathrm{PDB}=$ Vienna Pee Dee Belemnite, the international reference standard for ${ }^{13} \mathrm{C} /{ }^{12} \mathrm{C}$ measurements.

BDV can be used to monitor shifts in whole body metabolism. Although diet influences baseline BDV on a population scale, ${ }^{2}$ changes in the BDV over time within an individual can shed light on changes in the ratio of macronutrient oxidation, ${ }^{2}$ as well as the acute phase response to infection (i.e. whole body inflammation) due to fractionation (a term for shifts in the stable isotope ratio based on atomic weight of the isotope; see detailed explanation below). ${ }^{\mathbf{3 , 4 , 6}}$

\section{The basic science of fractionation}

The atomic weight of carbon listed on the periodic table of elements is $12.011 \mathrm{~g} \mathrm{~mol}^{-1}$. The reason this number is 12.011 and not 12.000 is that approximately $1 \%$ of the carbon in the universe is ${ }^{13} \mathrm{C}$, which weighs 1 atomic mass unit more. The ubiquitous usage of atomic weight in calculations performed by chemists and biochemists reinforces the notion that any organic compound will contain $1 \%$ of its carbon in the form of ${ }^{13} \mathrm{C}$. This assumption is valid and useful because ${ }^{13} \mathrm{C}$ and ${ }^{12} \mathrm{C}$ are, for most purposes, chemically interchangeable and the organic compounds of which they are constituents are ostensibly indistinguishable. However, ${ }^{13} \mathrm{C}$ and ${ }^{12} \mathrm{C}$ do differ from each other in one important way; ${ }^{13} \mathrm{C}$ is more than $8 \%$ heavier than ${ }^{12} \mathrm{C}$. This difference in mass is large enough that molecules containing ${ }^{13} \mathrm{C}$ behave differently in reactions than molecules containing exclusively ${ }^{12} \mathrm{C}$. This difference in reactivity is even more pronounced when the chemical bonds that are changing involve the ${ }^{13} \mathrm{C}$ atom. The result is that the isotope ratio on one side of a chemical reaction will differ from the isotope ratio on the other side of the chemical reaction even at equilibrium. This is referred to as isotope fractionation. Isotope fractionation can derive from the thermodynamic (equilibrium) isotope effect, the kinetic isotope effect, or by enzymatic discrimination against ${ }^{13} \mathrm{C}$ structures.

Isotope fractionation is the chemical phenomenon that is the basis for relating the dynamic relationship between changes in metabolism and changes in the observed ratio of ${ }^{13} \mathrm{CO}_{2} /{ }^{12} \mathrm{CO}_{2}$ in breath, which we describe in detail elsewhere in this review. This isotope ratio is termed the delta value $\left(\delta^{13} \mathrm{C}\right)$ when it is reported with respect to the internationally recognized standard isotope ratio of PDB, which is 0.0112372 (eqn (1)). A positive $\delta^{13} \mathrm{C}$ occurs when the measured isotope ratio is higher than PDB whereas a negative $\delta^{13} \mathrm{C}$ occurs when the measured isotope ratio is lower than PDB. Since PDB contains the heaviest known naturally occurring ${ }^{13} \mathrm{C} /{ }^{12} \mathrm{C}$ ratio, all measurements of the natural abundance of carbon isotopes are negative. Chemical bonds involving heavy forms of an atom have lower vibrational energy than bonds involving the lighter atomic forms and are therefore less reactive. This is known as the primary isotope effect. A similar, but smaller effect in reaction rates occurs for molecules containing ${ }^{13} \mathrm{C}$ but where the chemical bond undergoing reaction does not itself contain the ${ }^{13} \mathrm{C}$ atom. This is known as the secondary isotope effect.

Observing the $\delta^{13} \mathrm{C}$, or more accurately the change in $\delta^{13} \mathrm{C}$ over time, is a tremendously powerful and sensitive means of detecting and measuring changes in steady-state systems. For example, aerobic respiration within an organism is the process whereby nutrients in the form of carbohydrates, fat and proteins are converted with oxygen into chemical potential energy in the form of ATP. A major byproduct of aerobic respiration is carbon dioxide. The $\delta^{13} \mathrm{C}$ for the carbon dioxide produced from aerobic respiration over time will remain constant so long as the system is at a steady state, meaning that the composition of nutrients used as sources for the various biochemical reactions involved do not change. However, disruption in the source, composition and utilization of nutrients will cause a change in $\delta^{13} \mathrm{C}$ because nutrients are isotopically distinct and because there is an isotopic fractionation in each and every biochemical reaction in the metabolic pathway.

\section{Regional differences in baseline diet}

The $\delta^{13} \mathrm{C}$ of the diet will define the isotopic makeup of the body ${ }^{7}$ and thus diet can influence the baseline BDV. Thus, the population healthy baseline BDV varies by region with European countries at $\sim-23 \%$, the United States at $\sim-21 \%$, and Japan falling somewhere between these two countries. ${ }^{7}$ The differences are based mainly on the primary plant carbon source. Plants are classified into two categories important to the isotopic makeup of carbon structures: C3 and C4 plants. ${ }^{7}$ During photosynthesis, plants remove $\mathrm{CO}_{2}$ from the atmosphere and use it to build carbohydrates and amino acids to fuel metabolism and growth through photosynthesis. Plants fix carbon using an enzyme complex known as rubisco. ${ }^{8}$ The rubisco enzyme complex strongly discriminates against ${ }^{13} \mathrm{CO}_{2},{ }^{9}$ thus plant carbon structures are isotopically lighter than the atmosphere. $\mathrm{C} 3$ plants scavenge $\mathrm{CO}_{2}$ directly from the atmosphere, and thus are isotopically light compared to atmospheric carbon. ${ }^{10}$ On the other hand, $\mathrm{C} 4$ plants are adapted to a low $\mathrm{CO}_{2}$ atmosphere and thus scavenge and compartmentalize the atmospheric $\mathrm{CO}_{2}$ prior to photosynthesis. ${ }^{10}$ Since the $\mathrm{CO}_{2}$ is compartmentalized prior to photosynthesis the mass action effect causes all of the compartmentalized $\mathrm{CO}_{2}$ to proceed through photosynthesis despite the discrimination against ${ }^{13} \mathrm{CO}_{2}$ by the rubisco enzyme complex. The typical isotopic signature of $\mathrm{C} 3$ plants (e.g. rice, wheat, potatoes) is $\sim-27 \%$, while the typical isotopic signature of $\mathrm{C} 4$ plants (e.g. corn and sugar cane) is $\sim-11 \%{ }^{10}$ Since the modern diet is composed of a mixture of $\mathrm{C} 3$ and $\mathrm{C} 4$ plants as primary producers, the isotopic composition of the human diet has an intermediate isotopic signature. European countries have a diet that consists of more C3 plant sources and fewer C4 plant sources compared to the US. ${ }^{711-13}$ Japanese carbon sources may derive from C3 plants combined with a diet high in fish (algae plant source). ${ }^{\mathbf{7 1 1 , 1 2 , 1 4 , 1 5}}$ Although a baseline delta value of a person/ population ratio does not affect the ability to detect changes in metabolism in health or disease via the BDV, for these changes to have meaning the diet must remain relatively stable. 
Changes in diet must be noted and accounted for when interpreting the BDV. ${ }^{16}$

\section{Stable isotopes of carbon to track nutrition}

Isotopically speaking "we are what we eat", at least for carbon. ${ }^{17}$ Carbon is a conservative recorder of our diet, and as such, allows for the determination of dietary information and nutritional status. Changes in the isotopic signature of a diet can be measured in biological samples, and the half-life of the change is different depending on the rate of turnover for a given sample. For example, when an animal is switched from a $\mathrm{C} 3$ to a $\mathrm{C} 4$ diet, the change is recorded in breath, via $\mathrm{BDV}$, on a time scale of minutes to hours, whereas changes in $\delta^{13} \mathrm{C}$ in blood plasma and red blood cells occur on a days to weeks time scale. ${ }^{18}$ Hair grown during the switch from C3 to C4 diets can be used as a historical marker of the diet change since growing hair will reflect the contemporary diet. ${ }^{19}$ In mammals, plasma, tissue and breath $\delta^{13} \mathrm{C}$ is used to determine regional differences in food consumption, migratory patterns and nutritional stress. ${ }^{20-23}$ In humans, breath $\delta^{13} \mathrm{C}$ has been utilized to monitor glucose metabolism, ${ }^{24,25}$ while plasma $\delta^{13} \mathrm{C}$ has been used to quantify the intake of processed sweetened foods, specifically high fructose corn syrup. ${ }^{2-28}$ With increasing incidence of diet-related illnesses, stable isotopes of carbon are an objective means to distinguish dietary patterns and the relationship with diseases.

\section{BDV changes due to altered macronutrient metabolism}

The body oxidizes macronutrients (i.e. carbohydrate, lipid and protein) to meet the daily energy requirement to maintain metabolism. Normally the ratio of macronutrient oxidation in people is $30-40 \%$ carbohydrate, $50-65 \%$ lipid, and $7-8 \%$ protein. ${ }^{29}$ Based on the isotopic signature of each macronutrient class, ${ }^{9}$ the BDV can be used to assess changes in the ratio of oxidation of macronutrient classes. ${ }^{2}$ Under normal conditions, the body does not "store" protein for energy, rather any protein oxidation is a result of normal protein turnover and/or oxidation of excess dietary protein (post-prandial protein oxidation), accounting for less than $10 \%$ of the total daily energy requirement. ${ }^{30}$ Assuming constant protein catabolism, the BDV can be used to monitor changes in the rate of oxidation of carbohydrate versus lipid. ${ }^{2}$ Although diet can influence the baseline delta value of carbohydrates and lipids in plasma and liver as well as breath $\mathrm{CO}_{2}{ }^{2}$ lipids are generally $\sim 3 \%$ more negative than carbohydrates. ${ }^{9,31}$ Due to the relative differences in their isotopic signature, large changes in the ratio of carbohydrate : lipid oxidation cause changes in the BDV. A shift in the carbohydrate : lipid oxidation ratio of $20 \%$ causes approximately $1 \%$ change in the $\mathrm{BDV} .^{29}$ Shifts in the carbohydrate : lipid oxidation ratio can be caused by exercise, long-term fasting or negative energy balance, or pathologic metabolic conditions.

\section{Stable isotopes of carbon during exercise}

During exercise the ratio of macronutrient oxidation can shift to proportional increases in carbohydrate or lipid oxidation depending on the intensity and duration of the activity. Increased glucose oxidation during moderate to heavy intensity exercise can cause an $\sim 1 \%$ increase in the BDV. ${ }^{29,32}$ Extended workouts at $50 \%$ of $\mathrm{VO}_{2 \max }$ (the so-called "fat burning zone") decrease BDV by $\sim 1-2 \%{ }^{\circ}{ }^{29,33}$

\section{Stable isotopes of carbon in assessing metabolic status}

Change in BDV can be associated with pathologic conditions that cause a large shift in the ratio of carbohydrate : lipid oxidation. For example, untreated type 1 diabetes causes reduced glucose availability to tissues and $\sim 2 \%$ drop in BDV. ${ }^{34}$ Long-term fasting (48 hours or longer) depletes glycogen stores and increases lipid oxidation to meet body needs. While short term fasting of 4 hours does not cause a drop in BDV, ${ }^{2}$ overnight fasting of approximately 8 hours causes a drop in BDV of $\sim 1 \%$ (ref. 21) and a 48 hour fast causes a $\sim 3 \%$ drop. ${ }^{2,3}$ The shift in BDV in conjunction with fasting led scientists to investigate the possibility of using BDV to monitor successful compliance with a calorically restricted diet during efforts to lose weight. $^{21}$ Volunteers consumed a $40 \%$ energy-deficit diet for 6 days, followed by a $50 \%$ energy excess for one day. Morning fasted BDV decreased by $\sim 1 \%$ over the course of 3 days of energy restriction and increased by $\sim 2 \%$ within $3-4$ hours of caloric overconsumption. ${ }^{21} \mathrm{BDV}$ may be a valuable indicator of the body's metabolic fuel usage in situations where large shifts in the macronutrient oxidation ratio are expected.

\section{Stable isotopes of carbon in infection}

Severe and/or systemic infections cause a whole body response termed the acute phase response (APR).${ }^{35}$ Within the first hour of the APR, release of preformed tumor necrosis factor alpha (TNF $\alpha$ ) and interleukin 1 (IL-1) induce changes in secondary metabolism..$^{36,37}$ Amino acids are rapidly released from skeletal muscle and used to make acute phase proteins or oxidized for fuel. ${ }^{38}$ Amino acids released during the APR fractionate based on the molecular weight of the amino acid. ${ }^{3,4}$ This fractionation follows the principles of the kinetic isotope effect. ${ }^{39}$ Amino acids and products with ${ }^{13} \mathrm{C}$ structures are less likely to undergo enzymatic action than the amino acids with the lighter carbon. The "heavier" carbon amino acids primarily remain as products of the APR while the "lighter" carbon amino acids are more likely to be completely oxidized to $\mathrm{CO}_{2}$. The end result of this phenomenon is that the ratio of ${ }^{13} \mathrm{CO}_{2} /{ }^{12} \mathrm{CO}_{2}$ in breath decreases during the APR (Fig. 1). This phenomenon was first discovered in the 1990s at the University of Wisconsin-Madison. ${ }^{3,40}$ In the original study, $\mathrm{CO}_{2}$ of mice injected with endotoxin had decreased ${ }^{13} \mathrm{CO}_{2}$ within the first two hours of challenge while blood proteins became heavier due to the 


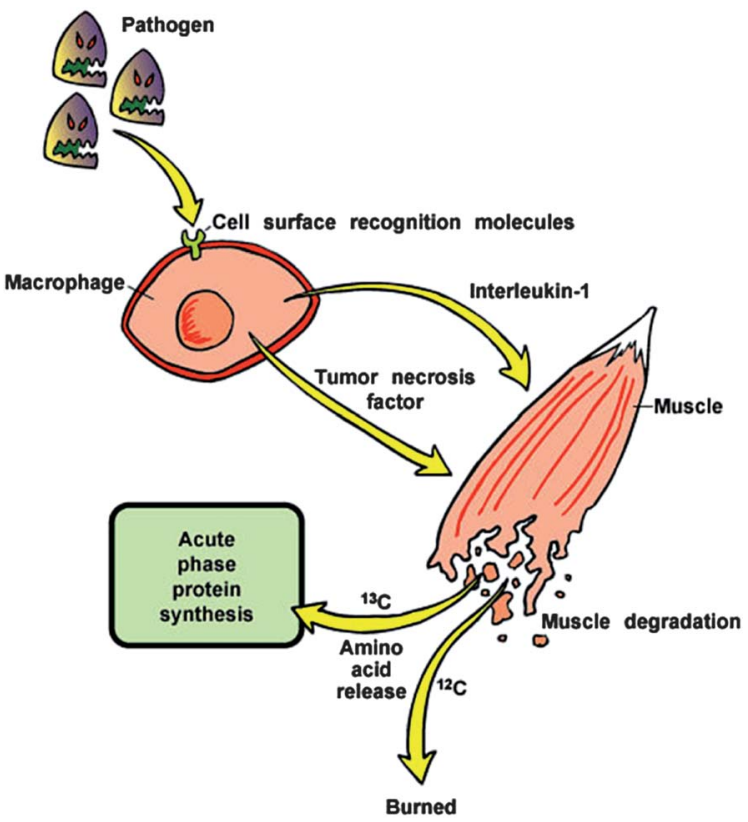

Fig. 1 Schematic representation of fractionation of carbon isotopes during the acute phase response to infection.

catabolic response. ${ }^{3,40}$ Further, Butz et al. ${ }^{4}$ conducted a study of carbon fractionation in mice and chicks with induced endotoxemia. The change in BDV was detected within 2 hours of post-injection of endotoxin with an increase in the isotopic weight of circulating amino acids. Carbon fractionation was shown to be specifically dependent on the acute phase response, since simple muscle wasting induced by dexamethasone treatment did not result in carbon fractionation (in order to fractionate carbon, the amino acids with heavy carbon must be incorporated into products, such as acute phase proteins). The phenomenon was later shown in rat and swine peritonitis models of sepsis where the change in BDV preceded hypotension by 12 to 18 hours, ${ }^{6,41}$ and in mechanically ventilated pediatric patients with and without systemic inflammatory response syndrome (SIRS). ${ }^{42}$

\section{Conclusions}

Application of the measurement of natural stable isotope variations has traditionally fallen into the field of geochemistry. As this review demonstrates, there are also numerous potential applications suitable for the field of health sciences as well. Specifically regarding natural stable isotope fractionation of carbon, applications include detection of altered macronutrient oxidation related to exercise, changing energy balance and altered intake, as well as changes in inflammatory or immune status. As the health science research fields tackle the need for earlier disease detection and personalized medicine, demand grows for new and improved ways to monitor the individual status and response to treatments or interventions. These emerging roles for the measurement of naturally abundant stable isotopes of carbon in health and disease can help meet that need.

\section{Conflicts of interest}

Daniel E. Bütz has an ownership interest in Isomark, LLC, which has licensed the technology discussed in this publication.

\section{Acknowledgements}

The authors would like to thank Professor Warren Porter and Bill Feeny for providing the artwork presented in Fig. 1.

\section{References}

1 M. B. Jaffe, Anesth. Analg., 2008, 107, 890-904.

2 D. A. Schoeller, C. Brown, K. Nakamura, A. Nakagawa, R. S. Mazzeo, G. A. Brooks and T. F. Budinger, Biomed. Mass Spectrom., 1984, 11, 557-561.

3 K. A. Hatch, K. A. Sacksteder, I. W. Treichel, M. E. Cook and W. P. Porter, Biochem. Biophys. Res. Commun., 1995, 212, 719726.

4 D. E. Butz, M. E. Cook, H. R. Eghbalnia, F. Assadi-Porter and W. P. Porter, Rapid Commun. Mass Spectrom., 2009, 23, 37293735.

5 E. H. Wahl, B. Fidric, C. W. Rella, S. Koulikov, B. Kharlamov, S. Tan, A. A. Kachanov, B. A. Richman, E. R. Crosson, B. A. Paldus, S. Kalaskar and D. R. Bowling, Isot. Environ. Health Stud., 2006, 42, 21-35.

6 D. E. Butz, S. L. Morello, J. Sand, G. N. Holland and M. E. Cook, J. Anal. At. Spectrom., 2014, DOI:10.1039/ c3ja50340b.

7 K. Nakamura, D. A. Schoeller, F. J. Winkler and H. L. Schmidt, Biomed. Mass Spectrom., 1982, 9, 390-394.

8 I. Andersson and T. C. Taylor, Arch. Biochem. Biophys., 2003, 414, 130-140.

9 M. J. DeNiro and S. Epstein, Science, 1977, 197, 261-263.

10 H. W. Yeh and W. M. Wang, Proc. Natl. Sci. Counc., Repub. China, Part B: Life Sci., 2001, 25, 137-147.

11 R. Bol and C. Pflieger, Rapid Commun. Mass Spectrom., 2002, 16, 2195-2200.

12 L. A. Chesson, D. W. Podlesak, A. H. Thompson, T. E. Cerling and J. R. Ehleringer, J. Agric. Food Chem., 2008, 56, 40844091.

13 S. A. Macko, G. Lubec, M. Teschler-Nicola, V. Andrusevich and M. H. Engel, FASEB J., 1999, 13, 559-562.

14 O. Amitai, S. Holtze, S. Barkan, E. Amichai, C. Korine, B. Pinshow and C. C. Voigt, J. Exp. Biol., 2010, 213, 26932699.

15 L. J. Gay, Y. Schutz, V. DiVetta, P. Schneiter, L. Tappy and E. Jequier, Int. J. Obes. Relat. Metab. Disord., 1994, 18, 591595.

16 K. D. Nakamura, D. A. Schoeller, F. J. Winkler and H. L. Schmidt, Biomed. Mass Spectrom., 1987, 9, 390-394.

17 D. A. Schoeller, M. Minagawa, R. Slater and I. R. Kaplan, Ecol. Food Nutr., 1986, 18, 159-170.

18 D. W. Podlesak, S. R. McWilliams and K. A. Hatch, Oecologia, 2005, 142, 501-510. 
19 L. K. Ayliffe, T. E. Cerling, T. Robinson, A. G. West, M. Sponheimer, B. H. Passey, J. Hammer, B. Roeder, M. D. Dearing and J. R. Ehleringer, Oecologia, 2004, 139, 11-22.

20 T. Deschner, B. T. Fuller, V. M. Oelze, C. Boesch, J. J. Hublin, R. Mundry, M. P. Richards, S. Ortmann and G. Hohmann, Rapid Commun. Mass Spectrom., 2012, 26, 69-77.

21 L. D. Whigham, D. E. Butz, L. K. Johnson, D. A. Schoeller, D. H. Abbott, W. P. Porter and M. E. Cook, Int. J. Obes., 2013, in press.

22 K. A. Hatch, K. A. Sacksteder, I. W. Treichel, M. E. Cook and W. P. Porter, Biochem. Biophys. Res. Commun., 1995, 212, 719-726.

23 C. C. Voigt, L. Baier, J. R. Speakman and B. M. Siemers, J. Exp. Biol., 2008, 211, 2233-2238.

24 S. Normand, C. Pachiaudi, Y. Khalfallah, R. Guilluy, R. Mornex and J. P. Riou, Am. J. Clin. Nutr., 1992, 55, 430435.

25 E. L. Dillon, M. Janghorbani, J. A. Angel, S. L. Casperson, J. J. Grady, R. J. Urban, E. Volpi and M. Sheffield-Moore, Diabetes Care, 2009, 32, 430-435.

26 C. M. Cook, A. L. Alvig, Y. Q. Liu and D. A. Schoeller, J. Nutr., 2010, 140, 333-337.

27 A. H. Jahren, C. Saudek, E. H. Yeung, W. H. Kao, R. A. Kraft and B. Caballero, Am. J. Clin. Nutr., 2006, 84, 13801384.

28 E. H. Yeung, C. D. Saudek, A. H. Jahren, W. H. Kao, M. Islas, R. Kraft, J. Coresh and C. A. Anderson, Am. J. Epidemiol., 2010, 172, 1045-1052.
29 J. F. Gautier, F. Pirnay, B. Jandrain, M. Lacroix, F. Mosora, A. J. Scheen and P. J. Lefebvre, J. Appl. Physiol., 1993, 74, 133-138.

30 L. J. Mandarino, A. Consoli, A. Jain and D. E. Kelley, Am. J. Physiol., 1996, 270, E463-E470.

31 E. Melzer and H. L. Schmidt, J. Biol. Chem., 1987, 262, 81598164.

32 T. J. Barstow, D. M. Cooper, S. Epstein and K. Wasserman, J. Appl. Physiol., 1989, 66, 936-942.

33 A. R. Coggan, D. L. Habash, L. A. Mendenhall, S. C. Swanson and C. L. Kien, J. Appl. Physiol., 1993, 75, 70-75.

34 B. S. Jacobson, B. N. Smith and A. V. Jacobson, Biochem. Biophys. Res. Commun., 1972, 47, 398-402.

35 M. J. Delano and L. L. Moldawer, Nutr. Clin. Pract., 2006, 21, 68-81.

36 M. Yang, Ph.D. thesis, University of Wisconsin, 2002.

37 D. E. Butz, G. Li and M. E. Cook, J. Nutr. Biochem., 2006, 17, 735-741.

38 O. Zamir, P. O. Hasselgren, S. L. Kunkel, J. Frederick, T. Higashiguchi and J. E. Fischer, Arch. Surg., 1992, 127, 170-174.

39 L. L. Tieszen, T. W. Boutton, K. G. Tesdahl and N. A. Slade, Oecologia, 1983, 57, 32-37.

40 W. P. Porter, I. W. Treichel and M. E. Cook, US Pat., US005912178, 1999.

41 D. E. Butz, M. E. Cook, W. P. Porter and F. Assadi-Porter, FASEB J., 2010, 24, 752.4.

42 J. P. Boriosi, D. G. Maki, R. A. Yngsdal-Krenz, E. R. Wald, W. P. Porter, M. E. Cook and D. E. Butz, J. Anal. At. Spectrom., 2014, DOI: 10.1039/c3ja50331c. 